\title{
Effect of Biotin Deficiency on the Composition of Intestinal Microflora in Osteogenic Disorder Shionogi Rats
}

\author{
Michio KomaI, ${ }^{1, *}$ Yuji Furukawa, ${ }^{1}$ Hiroichi Sato,${ }^{1}$ Etsuo Yokota, ${ }^{2}$ \\ Hiroaki IsHIKo, ${ }^{2}$ and Shuichi KIMURA ${ }^{1}$ \\ ${ }^{1}$ Laboratory of Nutrition, Faculty of Agriculture, Tohoku University, \\ Aoba-ku, Sendai 981, Japan \\ ${ }^{2}$ Mitsubishi Yuka Bio-Clinical Laboratories, Inc., \\ Itabashi-ku, Tokyo 175, Japan
}

(Received June 28, 1993)

\begin{abstract}
Summary The present study was undertaken to clarify the difference in the intestinal microflora between biotin-deficient and control groups of osteogenic disorder Shionogi rats (ODS). Thirteen four-week-old, male ODS rats weighing $70 \mathrm{~g}$ on average were used. Both the biotindeficient and the control rats were fed a biotin-deficient diet, but the control rats were administered biotin $(100 \mu \mathrm{g})$ intraperitoneally once a week and the deficient rats were administered a comparable volume of saline. After feeding for 101 days, the cecal microflora was compared between the two groups by microbiological assay. The number of total aerobes $(p<0.01)$ and total anaerobes $(p<0.02)$ was higher in the biotindeficient group than in the control group. The overall total anaerobes/ total aerobes ratio was about 1,000 for the control group and 100 for the deficient group. This was mainly due to an increase in the numbers of the aerobic species Staphylococcus $(p<0.005)$ and Enterobacteriaceae $(p<$ $0.02)$ in the deficient group. In the present study biotin was administered intraperitoneally to the control rats, but the composition of the experimental diet (20\% egg white diet) was exactly the same for both the control and the biotin-deficient groups. Therefore, the results of the present experiment indicate that peripherally administered biotin can modify the intestinal microflora, probably via humoral changes.
\end{abstract}

Key Words: biotin deficiency, intestinal microflora, osteogenic disorder rats

Biotin deficiency can be achieved by feeding raw egg white as a source of

${ }^{*}$ To whom correspondence should be addressed. 
avidin, a protein that binds biotin highly specifically and strongly in the gut of man and animals $[1,2]$. The major characteristics of pathological symptoms of biotin deficiency are growth reduction, anorexia, depigmentation, seborrheic dermatitis, and alopecia [3, 4]. Furukawa et al. showed for the first time that the lumbo-sacral portion of the spine of biotin-deficient Wistar rats became arched [5], and the result was in agreement with the observation reported by Sallivan et al. [6]. The bone disorder caused by the biotin deficiency was attributed to a depression in collagen synthesis, which requires ascorbic acid for proline hydroxylation $[7,8]$.

In clinical studies Makino et al. [9] reported that the serum biotin level in psoriasis vulgaris and palmoplantar pustulosis patients was significantly less than in normal subjects, and it was equal to that of normal healthy infants. They also observed a high incidence of osteosclerosis and absorption of clavicular bone, especially in palmoplantar pustulosis patients. They treated patients having these syndromes with biotin and obtained successful results; i.e., 70\% $(35 / 50)$ of the patients with psoriasis vulgaris and $57 \%$ (17/30) with palmoplantar pustulosis showed an improvement of their dermatitis. Furthermore, they also reported several successful cases of biotin treatment of palmoplantar pustulosis patients who suffered pain in their clavicula [9]. Makino et al. speculated that there are several factors responsible for psoriasis vulgaris and palmoplantar pustulosis, and pointed out that intestinal microflora is one of the factors that play an important role in these syndromes because antibiotic treatment of such patients is occasionally effective. However, until now there have been few studies on the relationship between the biotin deficiency and the intestinal microflora.

Recently, the developmental mechanism of the bone disorder induced by ascorbic acid or biotin deficiency has been studied in osteogenic disorder Shionogi (ODS) rats that have a hereditary defect in their ascorbic acid-synthesizing ability [10]. The ODS rats, fed a biotin-deficient diet containing raw egg white, were afflicted with a bone abnormality including a hunch in the vertebral column [11]. However, the contribution of the intestinal microflora to biotin metabolism has not yet been thoroughly examined. We reported earlier that germ-free mice develop the symptoms of biotin deficiency much easier than their conventional counterparts [8], which means that the intestinal microflora produce biotin in the intestine and may contribute to the host nutrition. There are several reports that have shown a positive contribution of bacterially produced biotin in the distal intestine (large intestine) of the host [12-14].

The present study was undertaken to clarify the difference in the intestinal microflora between the biotin deficient and the control ODS rats, and to obtain useful information on the relationship between biotin deficiency and intestinal flora-related disorders such as psoriasis vulgaris and palmoplantar pustulosis. 


\section{MATERIALS AND METHODS}

Thirteen four-week-old, male osteogenic disorder (ODS) od/od rats [10] weighing $70 \mathrm{~g}$ on average were generously supplied by Aburahi Laboratories, Shionogi \& Co., Ltd., Koka, Japan and were divided into two groups. All animals were fed a biotin-deficient diet (20\% freeze-dried raw egg white as a protein source). The composition of the experimental diet was reported previously [ 15 , 16]. The rats were given free access to the semisynthetic diet and drinking water; and the control and the biotin-deficient groups were given an intraperitoneal injection of $0.5 \mathrm{ml}$ of saline containing $100 \mu \mathrm{g}$ of biotin and saline only, respectively, once a week. The animals were kept in individual cages with a wire-mesh floor. Diet containers, water bottles, and cages were kept as clean as possible to prevent coprophagy.

After the rats had been fed the experimental diet for 101 days, the control and biotin-deficient animals were used for microbiological assays. The rats were sacrificed under anesthesia with ethyl ether, and the cecal contents were obtained by cutting the intestinal tract with sterile instruments. The analytical method used for assessment of the gastrointestinal microflora was essentially the same as that of Mitsuoka et al. $[17,18]$. The cecal contents were transferred to test tubes containing transfer medium (Table 1), and the tubes were then filled with carbon dioxide gas in order to minimize the inactivation of anaerobes.

The specimens were cultured within $20 \mathrm{~h}$ after collection. After having been thoroughly mixed, the specimens were serially diluted from $10^{-1}$ to $10^{-8}$ with an anaerobic diluent [17]. From each dilution, $0.05 \mathrm{ml}$ aliquots were spread on three non-selective agar plates: modified Eggerth-Gagnon (EG) agar (Eiken Co., Ltd., Tokyo) [18] and glucose blood liver (BL) agar (Eiken) [18] for anaerobes, and triptycase soy blood (TS) agar (BBL Microbiology System, Cockeyville, MD) for aerobes [18], as well as on 11 selective agar plates: deoxycholate hydrogen sulfide lactose (DHL) agar (Eiken) for Enterobacteriaceae [18], triphenyltetrazolium chloride-acridine orange-thallous sulfate aesculin crystal violet (TATAC) agar (Difco Laboratories, Detroit, MI) for Enterococcus spp. and Streptococcus spp. [18], nalidixic acid cetrimide (NAC) agar (Eiken) for Pseudomonas aeruginosa,

Table 1. Composition of transfer medium.

\begin{tabular}{lc}
\hline Brain heart infusion (Difco) & $37.0 \mathrm{~g}$ \\
Resazurin (0.1\% soln, Tokyo Kasei) & $0.5 \mathrm{ml}$ \\
Agar (Difco) & $1.0 \mathrm{~g}$ \\
L-Cysteine $\mathrm{HCl} \cdot \mathrm{H}_{2} \mathrm{O}$ (Kokusan Kagaku) & $0.5 \mathrm{~g}$ \\
$\mathrm{Na}_{2} \mathrm{CO}_{3}$ (Wako) & $4.0 \mathrm{~g}$ \\
Distilled water & up to $1,000 \mathrm{ml}$ \\
\hline
\end{tabular}

Whole cecal content obtained from each rat was transferred to butyl rubber-stoppered tubes containing the transfer medium, and filled with carbon dioxide gas and ice-cooled until later analysis. 
phenylethylalcohol egg yolk suspension (PEES) agar (Difco) for Staphylococcus spp. [18] (which species was further identified as coagulase-negative Staphylococcus [CNS] and -positive Staphylococcus [S. aureus]), potato dextrose (PD) agar (Difco) for yeasts and molds [18], neomycin-brilliant green-taurocholate-blood (NBGT) agar (Difco) for Bacteroides spp. [18], bifidobacteria-selective (BS) agar (Difco) for Bifidobacterium spp. [18], eubacterium-selective (ES) agar (Difco) for Eubacterium spp. [17], modified veillonella-selective (VS) agar (Difco) for Veillonella spp. and Megasphaera spp. [18], modified lactobacilli-selective (LBS) agar (BBL) for Lactobacillus spp. [18], and neomycin-Nagler (NN) agar (Difco) for lecithinase-positive Clostridium spp. [18].

Eight types of agar plates (EG, BL, NBGT, LBS, BS, VS, ES, and NN) were incubated at $37^{\circ} \mathrm{C}$ for 3 days in an anaerobic steel-wool jar filled with an atmosphere of oxygen-free $\mathrm{CO}_{2}$, and the other six (TS, DHL, NAC, TATAC, PEES, and PD) were incubated aerobically at $37^{\circ} \mathrm{C}$ for 24 to $48 \mathrm{~h}$. After incubation, each plate was examined by colony counting. The identification of the 23 bacterial groups and yeasts was made based on colonial and cellular morphology, Gram staining, spore formation, and aerobic growth. For the bacterial species identified, the bacterial number per gram of wet cecal contents was counted and converted into its logarithmic equivalent. The total viable counts were calculated from the sum of the total number of each bacterial species.

Statistical comparison of the two groups was performed by first determining population variances using the $F$-test. The two sample $t$-test was used to compare those cases of equal variance (17 cases) and Welch's correction was applied for the two cases of unequal variance.

\section{RESULTS}

A comparison of cecal microflora in the control and experimental groups is shown in Table 2. Dietary egg white, containing avidin, did not inhibit the bacterial growth in either group judging from the results of the profile and the total numbers of microorganisms found in the control and biotin-deficient groups ( $10^{9.74}$ and $10^{10.47}$, respectively). A significant increase was observed in the total number of the cecal microflora in the biotin-deficient rats $\left(10^{10.47}\right)$ compared with the biotin-sufficient (control) group $\left(10^{9.74}, p<0.02\right)$. The number of total aerobes in the biotin-deficient group $\left(10^{8.45}\right)$ was higher than that in the control group $\left(10^{6.70}, p<0.01\right)$, and among them the Staphylococcus spp. counts were 1,000 -fold higher $\left(10^{7.67}\right.$ vs. $\left.10^{4.69}, p<0.001\right)$ and the $E$. coli counts were 63 -fold higher $\left(10^{8.10}\right.$ vs. $10^{6.30}, p<0.02$ ). The number of the total anaerobes in the biotin-deficient group $\left(10^{10.47}\right)$ was also higher than that in the control group $\left(10^{9.74}, p<0.02\right)$; and among them the Eubacterium spp. counts were 13 -fold higher $\left(10^{9.32}\right.$ vs. $\left.10^{8.17}, p<0.005\right)$, the Clostridium spp. counts, 6-fold higher $\left(10^{8.88}\right.$ vs. $\left.10^{8.10}, p<0.05\right)$, and the Bacteroidaceae spp. counts, 5-fold higher $\left(10^{10.28}\right.$ vs. $\left.10^{9.56}, p<0.05\right)$ than those of the biotin-sufficient rats. The overall [total anaerobes/total aerobes] ratio was 
Table 2. The effect of biotin deficiency on the cecal microflora in osteogenic disorder Shionogi rats.

\begin{tabular}{|c|c|c|}
\hline \multirow{2}{*}{ Cecal microflora } & \multicolumn{2}{|c|}{$\begin{array}{c}\text { Mean } \pm \text { SD of } \log _{10} \text { (number of organisms per gram } \\
\text { of wet cecal content) }\end{array}$} \\
\hline & Control $(n=7)$ & Biotin deficient $(n=6)$ \\
\hline Enterobacteriaceae & $6.30 \pm 1.14(7 / 7)^{\mathrm{a}}(0.04 \%)^{\mathrm{b}}$ & $8.10 \pm 1.07(6 / 6)^{2}(0.43 \%)$ \\
\hline E. coli & $6.30 \pm 1.14(7 / 7)$ & $8.10 \pm 1.07(6 / 6)^{2}$ \\
\hline Enterococcus & $6.11 \pm 0.87(7 / 7)(0.02 \%)$ & $6.27 \pm 1.09(6 / 6)(0.01 \%)$ \\
\hline E. faecalis & $5.97 \pm 1.09(7 / 7)$ & $6.22 \pm 1.09(6 / 6)$ \\
\hline Staphylococus & $4.69 \pm 0.86(7 / 7)(0.00 \%)$ & $7.67 \pm 0.58(6 / 6)^{5}(0.16 \%)$ \\
\hline S. aureus & $3.62 \pm 1.05(6 / 7)$ & $6.60 \pm 0.96(6 / 6)^{5}$ \\
\hline CNS & $4.37 \pm 0.97(7 / 7)$ & $7.57 \pm 0.55(6 / 6)^{5}$ \\
\hline Bacillus & $0(0 / 7)$ & $0(0 / 6)$ \\
\hline Pseudomonas & $0(0 / 7)$ & $5.53(1 / 6)$ \\
\hline Yeasts (YLO) & $0(0 / 7)$ & $0(0 / 6)$ \\
\hline Total aerobes & $6.70 \pm 0.97(0.09 \%)$ & $8.45 \pm 0.89^{3}(0.96 \%)$ \\
\hline Bacteroidaceae & $9.56 \pm 0.35(7 / 7)(66.00 \%)$ & $10.28 \pm 0.66(6 / 6)^{1}(64.58 \%)$ \\
\hline B. fragilis group & $9.27 \pm 0.52(7 / 7)$ & $9.93 \pm 0.63(6 / 6)$ \\
\hline B. vulgatus & $9.28 \pm 0.58(5 / 7)$ & $9.45 \pm 0.82(6 / 6)$ \\
\hline B. distasonis & $8.90 \pm 0.25(5 / 7)$ & $9.52 \pm 0.64(5 / 6)$ \\
\hline B. uniformis & $8.50(1 / 7)$ & $8.60(1 / 6)$ \\
\hline B. thetaiotaomicron & $8.07 \pm 0.40(3 / 7)$ & $0(0 / 6)$ \\
\hline Bifidobacterium & $8.20 \pm 0.54(7 / 7)(2.88 \%)$ & $8.82 \pm 0.64(6 / 6)(2.24 \%)$ \\
\hline Eubacterium & $8.17 \pm 0.46(7 / 7)(2.69 \%)$ & $9.32 \pm 0.64(6 / 6)^{4}(7.08 \%)$ \\
\hline Peptostreptococcus & $8.51 \pm 0.56(7 / 7)(5.88 \%)$ & $8.92 \pm 0.64(6 / 6)(2.82 \%)$ \\
\hline Megasphaera & $0(0 / 7)$ & $0(0 / 6)$ \\
\hline Veillonella & $0(0 / 7)$ & $0(0 / 6)$ \\
\hline Lactobacillus & $8.03 \pm 0.50(7 / 7)(1.95 \%)$ & $7.94 \pm 1.77(5 / 6)(0.30 \%)$ \\
\hline Clostridium perfringens & $0(0 / 7)$ & $0(0 / 6)$ \\
\hline Clostridium others & $8.10 \pm 0.64(7 / 7)(2.29 \%)$ & $8.88 \pm 0.52(6 / 6)^{1}(2.57 \%)$ \\
\hline Total anaerobes & $9.74 \pm 0.28(99.91 \%)$ & $10.47 \pm 0.56^{2}(99.04 \%)$ \\
\hline Total & $9.74 \pm 0.28(100 \%)$ & $10.47 \pm 0.56^{2}(100 \%)$ \\
\hline
\end{tabular}

about 1,000 for the control group and 100 for the biotin-deficient group.

As for the percentage of the species of microorganisms, there was an increase in Staphylococcus spp. (176-fold $=0.1585 \%: 0.0009 \%)$, Enterobacteriaceae spp. (11-fold $=0.43 \%: 0.04 \%)$ and Eubacterium spp. $(2.6$-fold $=7.1 \%: 2.7 \%)$ in the biotin-deficient rats. However, there was a decrease in Lactobacillus spp. (6-fold = 0.3\%: 1.9\%), Enterococcus spp. (4-fold $=0.006 \%: 0.023 \%$ ) and Peptostreptococcus spp. (2-fold $=2.8 \%: 5.9 \%$ ); and no change in Bacteroidaceae spp. (64.6:66.1), Bifidobacterium spp. $(2.2: 2.9)$, and Clostridium spp. $(2.6: 2.3)$.

The aerobic species, Bacillus and yeasts were not detected in any animals of either group, and the species Pseudomonas was detected in only 1 out of 6 Vol. 15, No. 3, 1993 
biotin-deficient rats. The anaerobic species Megasphaera, Veillonella, and Clostridium perfringens were not detected in any animals of either group.

\section{DISCUSSION}

It is widely known that the composition of gastrointestinal microflora is influenced by the type of diet [19-21]. The overall counts of cecal microbes of the present experiment with ODS rats are comparable with the previously published results in which SD [22] and Wistar rats [23] were fed a commercial chow diet.

In the present study biotin was administered intraperitoneally to the control rats, but the components of the experimental diet (20\% egg white diet) were exactly the same for both the control and the biotin-deficient groups. Therefore, the results of the present experiment indicate that peripherally administered biotin can modify the intestinal microflora irrespective of the dietary components. The same kind of phenomenon was also well observed when experimental rats were exposed to environmental stress such as crowding [24], heat [24], and emotional stress [25], and probably occurs via hormone-related changes in the physiology of the gastrointestinal tract [24]. In the present study, it is also considered that the microfloral changes in the cecum of rats due to biotin deficiency are probably attributable to a secondary change, such as hormonal change caused by the physiology of biotin deficiency rather than dietary components.

It has been pointed out that the post-ileal segments of the intestine are primary regions for the fermentation and vitamin synthesis in most simple-stomached animals [26]. Recently, many reports have suggested that bacterially synthesized biotin in the cecum and colon can contribute to the host's nutrition, and many researchers have emphasized the potential physiological significance of the distal intestine (large intestine) as a site of vitamin absorption [8, 12-14, 27]. Therefore, it is possible to hypothesize that the intestinal flora plays an important role in the syndromes of psoriasis vulgaris and palmoplantar pustulosis.

Ishibashi et al. [28] found that Eubacterium spp., one of the most common anaerobic bacterial groups in normal fecal flora, was almost completely lacking in the feces of a patient with acrodermatitis enteropathica. However, it dramatically reappeared at a normal level after the administration of 5-chloro-7-iodo-8quinolinol (Entero-Vioform), with distinct improvements of all symptoms, including the low zinc level in serum.

Many microorganisms are known to be capable of biotin synthesis [29, 30]. Bacteroidaceae spp. and $E$. coli, which were detected as a major component of anaerobes and aerobes, respectively, in the present experiment, are also capable of biotin synthesis. The present experiment was undertaken by feeding egg white as a source of biotin-binding avidin, and thus the bacterially produced biotin in the intestine may not be absorbed, as it is already known that there is no degradation of avidin in the alimentary tract [31].

The present experiment demonstrates the necessity for identifying intestinal 
flora in patients of psoriasis vulgaris and pulmoplantar pustulosis. Further characterization like the present experiment may assist the clarification of the mechanisms of these unclear diseases. As a next step of our experiment we are now planning to characterize the intestinal microflora in patients with psoriais vulgaris and pulmoplantar pustulosis.

We thank Dr. Yoshimi Benno, The Institute of Physical and Chemical Research, Wako 351, Japan, for his professional advice and useful discussion.

\section{REFERENCES}

1. Sydenstricker, V.P., Singal, S.A., Briggs, A.P., DeVaughn, N.M., and Isbell, H. (1942): Observations on the "egg white injury" in man and its cure with a biotin concentrate. J. Am. Med. Assoc., 118, 1199-1200.

2. Green, N.M. (1975): Avidin. Adv. Protein Chem., 29, 85-133.

3. Whitehead, C.C. (1978): Effect of nutrient deficiencies in animals: Biotin, in CRC Hand Book Series in Nutrition and Food, Section E, Vol. 2, ed. by Rechcigl, M., CRC Press, West Palm Beach, FL, pp. 65-87.

4. Appel, J.A., and Briggo, G.M. (1980): Biotin, in Modern Nutrition in Health and Disease (6th ed.), ed. by Goodhart, R.S. and Shils, M.E., Lea and Febiger, Philadelphia, p.p. 274279.

5. Furukawa, Y., Sato, H., Komai, M., Ito, M., Maebashi, M., and Kimura, S. (1989): The 14th International Congress of Nutrition, Seoul, Korea, p. 589 (Abstracts).

6. Sallivan, M., Kolb, L., and Nicholls, J. (1942): Nutritional dermatoses in the rat. VII. Notes on the posture, gait and hypertonicity resulting from a diet containing unheated, dried egg white as the source of protein. Bull. Johns Hopkins Hosp., 70, 177-186.

7. Yoshinaka, R., Sato, M., and Ikeda, S. (1978): In vitro formation of collagen in skin of ascorbic acid-deficient rainbow trout. Bull. Jpn. Soc. Sci. Fish., 44, 1147-1150.

8. Komai, M., Fukasawa, H., Furukawa, Y., and Kimura, S. (1990): Metabolic characteristics of primary biotin deficiency established in germfree mice. Microecol. Therapy, 20, 63-67.

9. Makino, Y., Maebashi, M., Furukawa, Y., and Sato, T. (1985): Biotin therapy, in Hihuka MOOK, No. 2, Kanahara Shuppan Co., Ltd., pp. 237-244 (in Japanese).

10. Mizushima, Y., Harauchi, T., Yoshizaki, T., and Makino, S. (1984): A rat mutant unable to synthesize vitamin C. Experientia, 40, 359-361.

11. Furukawa, Y., Kinoshita, A., Sato, H., Kikuchi, H., Ohkoshi, S., Maebashi, M., Makino, Y., Sato, T., Ito, M., and Kimura, S. (1992): Bone disorder and reduction of ascorbic acid concentration induced by biotin deficiency in osteogenic disorder rats unable to synthesize ascorbic acid. J. Clin. Biochem. Nutr., 12, 171-182.

12. Scholtissek, J., Barth, C.A., and Hagemeister, H. (1990): Biotin supply by large bowel bacteria in minipigs: Evidence from intracaecal avidin. Br. J. Nutr., 64, 715-720.

13. Barth, C.A., Frigg, M., and Hagemeister, H. (1986): Biotin absorption from the hindgut of the pig. J. Anim. Physiol. Anim. Nutr., 55, 128-134.

14. Bowman, B.B., and Rosenberg, I.H. (1987): Biotin absorption by distal rat intestine. J. Nutr., 117, 2121-2126.

15. Furukawa, Y., Sato, H., Sakamoto, A., Koizumi, Y., Maebashi, M., Makino, Y., Sato, T., Ito, M., and Kimura, S. (1992): Inhibition of insulin secretion and increase of plasma non-esterified fatty acid induced by biotin deficiency in osteogenic disorder Shionogi rats. J. Clin. Biochem. Nutr., 12, 201-208.

16. Harper, A.E. (1959): Amino acid balance and imbalance. I. Dietary level of protein and amino acid imbalance. J. Nutr., 68, 405-418.

17. Mitsuoka, T., Ohno, K., Benno, Y., Suzuki, K., and Namba, K. (1976): Die Faekalflora bei

Vol. 15, No. 3, 1993 
Menschen. V. Mitteilung: Vergleich des neu entwickelten Verfahrens mit dem bisherigen ublichen Verfahren zur Darmfloraanalyse. Zentralbl. Bakteriol. Hyg. I. Abt. Orig. A, 234, 219-233.

18. Mitsuoka, T., Sega, T., and Yamamoto, S. (1965): Eine verbesserte Methodik der qualitativen und quantitativen Analyse der Darmflora von Menschen und Tieren. Zentralbl. Bakteriol. Parasitenkd. Infectionskr. Hyg. I. Abt. Orig. A, 195, 455-469.

19. Savage, D.C. (1986): Gastrointestinal microflora in mammalian nutrition. Annu. Rev. Nutr., 6, $155-178$.

20. Benno, Y., Honjo, S., and Mitsuoka, T. (1987): Effect of two-year milk-feeding on the gastrointestinal microflora of the cynomolgus monkey (Macaca fascicularis). Microbiol. Immunol., 31, 943-947.

21. Balmer, S.E., and Wharton, B.A. (1991): Diet and fecal flora in the newborn: Iron. Arch. Dis. Child., 66, 1390-1394.

22. Takahashi, M., Kametaka, M., and Mitsuoka, T. (1983): Influence of diets low in protein or lysine on the cecal flora of rats with reference to cecal contents. J. Nutr. Sci. Vitaminol., 29, 601-609.

23. Morishita, Y., and Miyaki, K. (1979): Effects of age and starvation on the gastrointestinal microflora and the heat resistance of fecal bacteria in rats. Microbiol. Immunol., 23, 455-470.

24. Suzuki, K., Harasawa, R., Yoshitake, Y., and Mitsuoka, T. (1983): Effects of crowding and heat stress on intestinal flora, body weight gain, and feed efficiency of crowding rats and chicks. Jpn. J. Vet. Sci., 45, 331-338.

25. Holdman, L.V., Good, I.J., and Moore, W.E.C. (1976): Human fecal flora: Variation in bacterial composition within individuals and a possible effect of emotional stress. Appl. Environ. Microbiol., 31, 359-375.

26. Christensen, K. (1980): Evaluation of the background for determination of vitamin requirements in pigs. Livest. Prod. Sci., 7, 569-590.

27. Sorrell, M.F., Frank, O., Thomson, A.D., Aquino, H., and Baker, H. (1971): Absorption of vitamins from the large intestine in vivo. Nutr. Rep. Int., 3, 143-148.

28. Ishibashi, Y., Nakabayashi, Y., Kukita, A., Benno, Y., and Mitsuoka, T. (1985): Abnormalities of fecal flora in patients with acrodermatitis enteropathica. J. Dermatol., 12, 219-225.

29. McCormick, D.B., and Wright, L.D. (1971): Metabolism of water-soluble vitamins, in Comprehensive Biochemistry, Vol. 21, ed. by Flarkin, M. and Stotz, E.H., Elsevier Publishing Company, Amsterdam, pp. 81-110.

30. Teraguchi, S., Ono, J., Kiyosawa, I., Fukuwatari, Y., Araki, K., and Okonogi, S. (1984): Vitamin production by bifidobacteria originated from human intestine. Nippon Eiyo Shokuryo Gakkaishi, 37, 157-164 (in Japanese).

31. Gyorgy, P., and Langer, B.W., Jr. (1968): Biotin, in The Vitamins (2nd ed.), Vol. 2, ed. by Sebrell, W.H., Jr. and Harris, R.S., Academic Press, London, New York, pp. 316-322. 